\title{
HACIA UNA POLÍTICA PÚBLICA DE ACCESO A LA INFORMACIÓN OFICIAL EN COLOMBIA
}

\section{ANÁLISIS DE COYUNTURA}

Por:

Patricia Alzate Jaramillo

Profesora

Escuela de Comunicación Social

Universidad del Valle

patricia.alzate@correounivalle.edu.co

\section{Resumen:}

El presente artículo elabora un análisis de coyuntura en torno al diseño y formulación de una política pública de acceso a la información en Colombia, a partir de la comparación de dos proyectos de ley. El primero liderado por congresistas de la Comisión Primera del Senado - proyecto de ley 210 de 2010; y el segundo -en este momento cursa trámite en el Senado- elaborado por la Plataforma Más Información Más Derechos -proyecto de ley "del derecho de acceso a la información"-. El documento se detiene en las dos primeras fases del ciclo de políticas públicas (policy cicle): la definición, construcción del problema y puesta en agenda pública, y la formulación de soluciones. El análisis parte del enfoque de las teorías mixtas sobre políticas públicas. Así mismo, el texto reflexiona en torno a la incidencia de organizaciones internacionales gubernamentales y no gubernamentales.

Palabras claves: análisis de políticas públicas, análisis de coyuntura, libertad de expresión, acceso a la información pública.

\begin{abstract}
:
This article makes a conjunctural analysis about the design and formulation of a public policy of access to the information in Colombia, beginning with the comparison of two law projects. The first one leaded by senators of Comisión Primera del Senado - law project 210 of 2010; and the second - nowadays processed in the Senado - made by the Plataforma Más Información Más Derechos - law project of "the right of access to the information"-. The document analysis the two first of the public policy phases: the definition, the construction of the problem and put in public agenda, and the formulation of solutions. The work approaches from the mixed theories on public policy (Roth, 2009:31). In the same way, the text consider about the incidence of international governmental and no governmental organizations.
\end{abstract}

Keywords: public policy analysis, situation analysis, freedom ofexpression, access to public information. 


\section{Presentación}

La perspectiva normativa en torno a las relaciones entre democracia y libertad de expresión destaca la importancia que para un sistema político democrático encarna la posibilidad de que los ciudadanos tengan los elementos de juicio para ejercer control sobre las instituciones estatales y para incentivar su participación en la vida pública, ya sea a través de los mecanismos tradicionales (votaciones, referéndums, etc.) o mediante procesos organizativos de la sociedad civil. A su vez, el derecho a la libertad de expresión, llevado al terreno de las interacciones sociales más cotidianas, aquellas que no necesariamente expresan las manifestaciones formales del ejercicio ciudadano o los procesos de organización social, supondría la interiorización de unos hábitos que deberían hacer parte de las prácticas culturales y de las normas de convivencia de una sociedad democrática: expresar un punto de vista, disentir, solicitar una información...

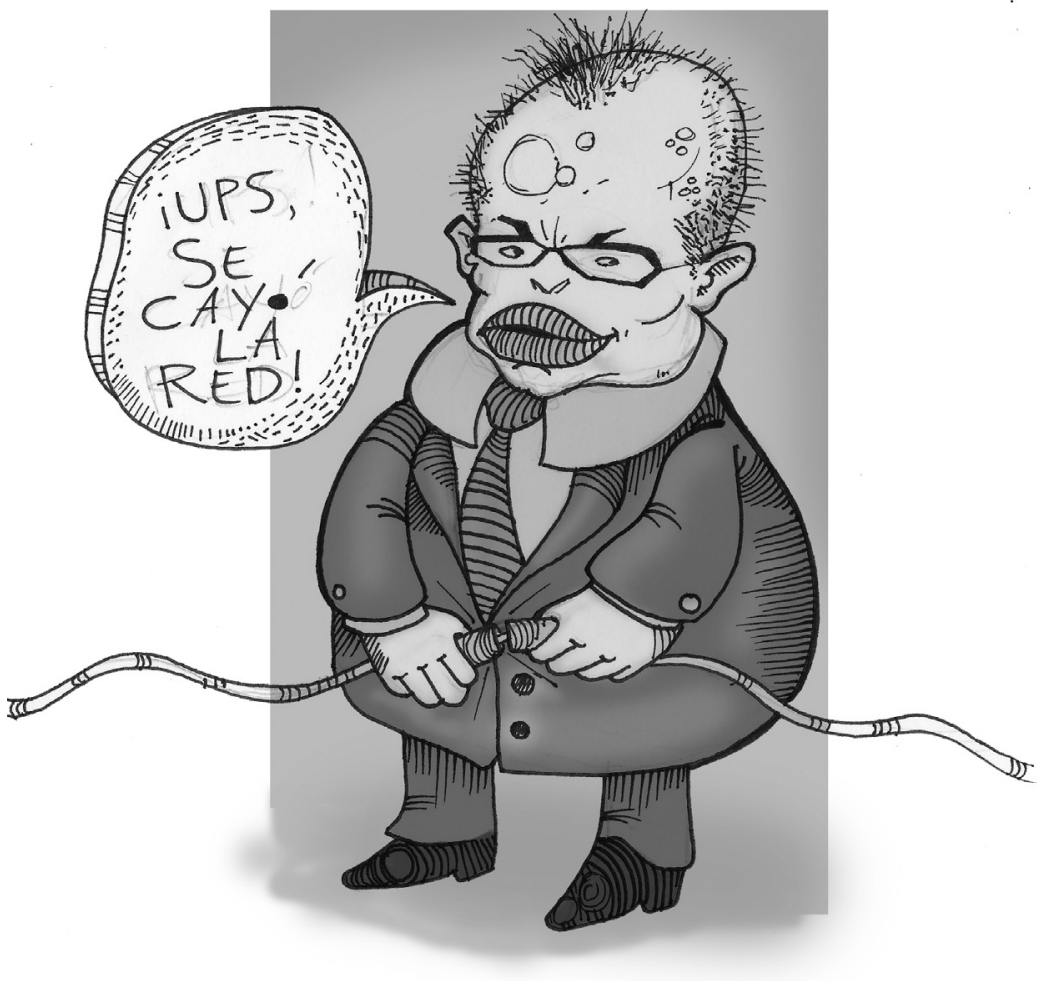

No obstante, en el caso colombiano la aplicabilidad de este derecho fundamental se enfrenta a una serie de tropiezos y obstáculos en los que convergen, por una parte, el poco conocimiento que se tiene del mismo y de sus implicaciones, en las esferas privada y pública; y por otra parte, la carencia de un engranaje institucional que garantice su cumplimiento efectivo. El derecho de los ciudadanos a acceder a informaciones de carácter público es un ejemplo en el que convergen ambas dificultades, más aún, en un contexto social y político como el colombiano, caracterizado por las secuelas de un conflicto armado de larga duración, por una extensa lista de casos de corrupción en instituciones estatales y privadas, y por la ausencia de una cultura política que fomente el reconocimiento de los derechos y deberes fundamentales.

El propósito de este artículo es revisar una de las dimensiones de la libertad de expresión - la del acceso a la información pública-, a partir de un análisis de coyuntura en torno a la elaboración de dos proyectos de ley que representan dos visiones del tema y de su puesta en la agenda política: el proyecto de ley 210 de 2010 "por medio del cual se crea la ley de transparencia y acceso a la información pública nacional, y se dictan otras disposiciones”, elaborado por el senador del partido conservador Carlos E. Barriga y que ya pasó la primera plenaria de la Comisión Primera del Senado de la República; y el proyecto de ley "del derecho de acceso a la información", elaborado por la Plataforma Más Información Más Derechos, compuesta por una serie de organizaciones sociales (ver más adelante) y que se encuentra en su fase de socialización en diferentes escenarios del país. Dada la etapa de incubación en que se encuentran ambas iniciativas, este análisis se centra en las dos primeras fases del ciclo de políticas (policy cicle), relativas a la identificación, construcción de problemas y agenda política, y a la formulación de soluciones (Roth, 2009:57). Por otra parte, teniendo en cuenta que se trata de la construcción de una política pública en desarrollo y de que, en consecuencia, no es claramente previsible lo que va a suceder con ella, es necesario situar su estudio desde una metodología propia de un análisis de coyuntura. Teniendo en cuenta lo anterior, este artículo se desarrolla de la siguiente manera: en primer lugar, explica el marco analítico del análisis de coyuntura; en segundo lugar, expone las dimensiones de la libertad de expresión y, en ella, las particularidades del derecho de acceso a la información pública en Colombia. Como tercer punto analiza la primera fase del ciclo a partir de la caracterización de los acontecimientos, escenarios, actores y su relación de fuerzas. En cuarto lugar, en relación con la fase de formulación de soluciones, explica las diferencias claves entre los dos proyectos de ley presentados. Por último, presenta una serie de conclusiones que se desprenden del análisis previo y los escenarios posibles para las siguientes fases del ciclo (toma de decisiones e implementación). 


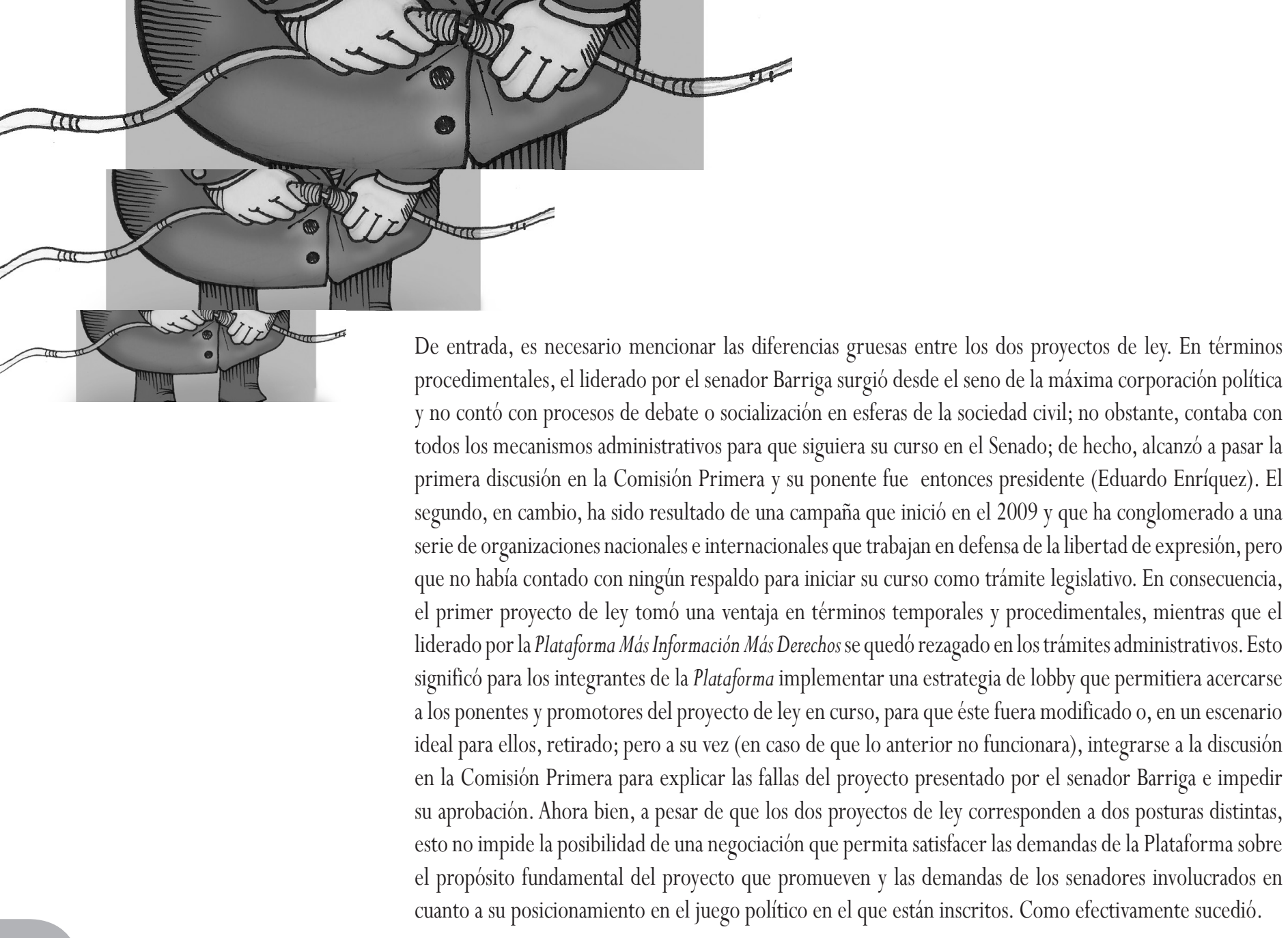

\section{Marco analítico}

La fase inicial por la cual atraviesa el posicionamiento del proyecto de ley sobre acceso a la información pública hace que el presente trabajo pueda considerarse como el intento de captar una instantánea del proceso: una especie de fotografía de alta definición que dé cuenta de los antecedentes, de las tensiones y de lo que está en juego en términos de formulación de una política pública. De ahí que sea necesario acudir a las herramientas que ofrece un análisis de coyuntura y partir de las limitaciones de estudiar un fenómeno que progresivamente está cambiando, de modo que no sólo sea posible describir las características del momento del análisis, sino también comprender la estructura social y política que lo soporta.

Este trabajo retoma la propuesta del documento "Cómo hacer un análisis de coyuntura (elementos para el análisis del político)", del Instituto Centroamericano de Estudios Políticos INCEP (2002), en el que esta perspectiva de análisis es caracterizada como "una concepción dialéctica de la relación entre la sociedad y los individuos, es decir, entre una estructura o formación socioeconómica que determina la práctica social y una práctica que transforma e influye en esa estructura" (Incep, 2002:14). En otras palabras, se refiere al análisis de una práctica que está determinada por unas causas estructurales pero que a su vez busca transformarlas; en el caso en cuestión, se trata de analizar cómo se identifica el tema de acceso a la información pública como un problema susceptible de ser formulado en una política considerando las condiciones estructurales que impiden el cabal cumplimiento de este derecho fundamental. Ahora bien, nos plantea el documento, debe tenerse en cuenta que para hablarse de una coyuntura se requiere de un estado de correlación de fuerzas compuesto por bloques de actores que defienden intereses de diverso orden (económicos, políticos o ideológicos) y ponen en escena estrategias y tácticas para el logro de sus objetivos: "Estas fuerzas sociales se manifiestan por sus prácticas, por sus proyectos de poder, por sus medios o instrumentos y por sus discursos” (Incep, 2002:17). 
En el caso específico del tema de acceso a la información, hay por lo menos dos bloques en tensión que representan perspectivas de la vida política, proyectos, medios y discursos diferentes, que, no obstante, se requieren mutuamente: de las organizaciones sociales, por una parte, y el del Estado, representado por los senadores ponentes de uno de los proyectos y por otras instancias gubernamentales eventualmente interesadas en el tema.

Teniendo en cuenta, pues, la pertinencia del análisis de coyuntura para el caso en cuestión, este trabajo hace el estudio desde las siguientes categorías: a) Identificación de los acontecimientos: dimensión social del tema y sus implicaciones en el contexto de un sistema político democrático; antecedentes externos e internos que justifican la puesta en agenda pública del tema de acceso a la información pública; b) Actores y escenarios: análisis de los espacios en los cuales el tema adquiere valor para determinados sectores; en este caso los escenarios propios de organizaciones sociales que propugnan por el tema (foros, reuniones, visitas, talleres de capacitación, etc.) y el del sistema político convencional (Congreso, entidades estatales y partidos políticos); c) Relación de fuerzas: análisis de lo que está en juego para los bloques en tensión. Por último, debe considerarse que este análisis se centra prioritariamente en el punto de vista de las organizaciones que conforman la Plataforma Más Información Más Derechos, a través de la cual obtuve la información documental requerida y a dos de cuyos integrantes entrevisté para este documento: la politóloga Francy Milena Alba, de la Corporación Transparencia por Colombia, y al abogado EmmanuelVargas, de la Fundación para la Libertad de Prensa, FLIP ${ }^{1}$.

Con respecto a las tendencias en el análisis de políticas públicas, este trabajo se centra, como ya se ha expresado, en las dos primeras fases del ciclo. A su vez, asume el enfoque de las teorías mixtas (Roth, 2009:31) teniendo en cuenta las influencias y dependencias mutuas entre el Estado y la sociedad en la construcción, formulación e implementación de una política pública como la del acceso a la información: tanto al Estado como a las organizaciones sociales que la promueven logran ganancias con ella. Como plantea Roth, "se trata, también, en cierta forma, de sustituir la búsqueda de las relaciones causales univocas para tratar de aprehender la sociedad como un tejido de relaciones más complejas, de interrelaciones más que de relaciones, de interdependencia más que de dependencia". (2009: 31). No obstante lo anterior, reitero, el punto de vista desde el cual se analiza esta interrelación es el de las organizaciones sociales, lo cual hace a este análisis más cercano a las teorías centradas en la sociedad que en las del Estado - una especie de teoría mixta, con énfasis en la sociedad, si se quiere-. En ese sentido, aborda elementos de las teorías de redes (networks theory). Recoge también aportes de Gioandomenico Majone (1997) y Pierre Muller (2006) en lo relativo a los procesos de debate de las políticas públicas. Por último, el texto retoma algunos elementos de Murray Edelman en torno al modo como los problemas políticos se ponen en agenda en los medios de comunicación (2002).

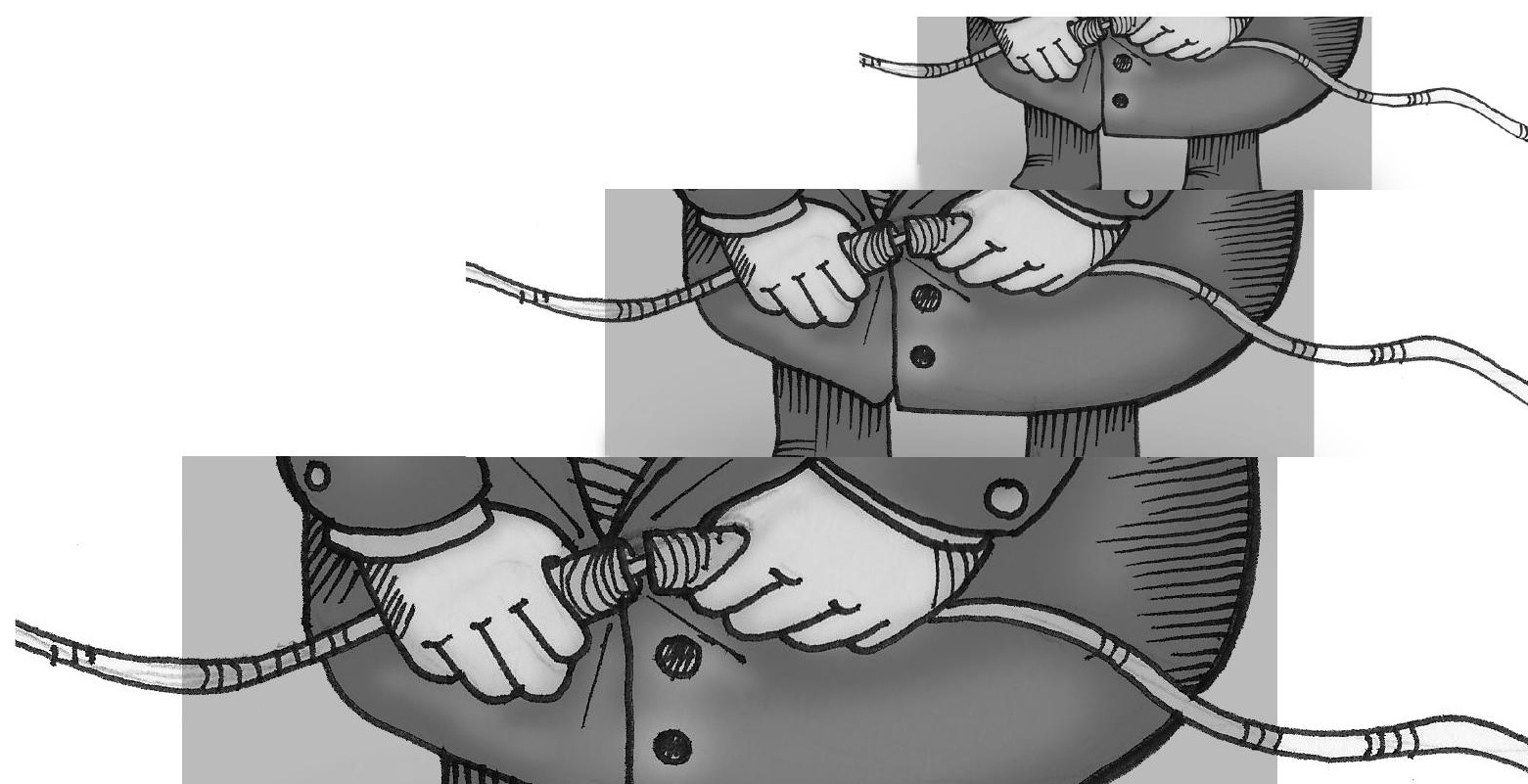




\section{Dimensión de los acontecimientos: el acceso a la información pública como un problema de política pública}

\author{
Todo individuo tiene derecho a la libertad de opinión y de \\ expresión; este derecho \\ incluye el no ser molestado a causa de sus opiniones, el de \\ investigar y recibir \\ informaciones y opiniones, y el de difundirlas, sin limitación de \\ fronteras, por cualquier \\ medio de expresión. \\ Artículo 19- Declaración Universal de los Derechos Humanos
}

\section{La libertad de expresión y el derecho de acceso a la información pública}

Pese a su indiscutible estatuto como derecho fundamental y a su carácter individual y colectivo, en torno a la libertad de expresión hay una serie diversa de debates. Por una parte, por la falta de precisión sobre lo que ella cobija: ¿cuáles son las relaciones y diferencias, por ejemplo, entre libertad de expresión, libertad de opinión, libertad de información o libertad de prensa? ¿Cuáles son los límites y alcances de las demandas por injuria y calumnia en investigaciones periodísticas y en columnas de opinión? Por otra parte, por sus alcances en contextos políticos que incluso siendo democráticos generan presiones a sus críticos y opositores: señalamientos de periodistas como terroristas, interceptaciones ilegales, cierre de canales de televisión, presiones a través de la pauta publicitaria, etc. También por sus limitaciones en términos del acceso a medios de expresión o sobre sus relaciones con el capital económico. En torno a estas diversas lecturas sobre la libertad de expresión se plantea en un informe de la Corporación Dejusticia: «... Es claro que se trata también de un derecho complejo, pues colisiona en forma permanente con otros derechos y bienes fundamentales (enmarcados en una democracia), como lo ilustra, por citar un solo ejemplo, la clásica y estudiadísima tensión entre la intimidad personal y la libertad informativa de los periodistas. Es, pues, un derecho que suscita polémicas jurídicas y políticas recurrentes"(Botero et al, 2005). Sin menoscabo de la importancia de estos debates, de acuerdo a la Relatoría Especial para la Libertad de Expresión de la Organización de Estados Americanos OEA, este derecho cumple con tres funciones fundamentales²:

- Proteger el derecho individual de cada persona a pensar por sí misma y a compartir informaciones y pensamientos propios y ajenos.

- Es una condición indispensable para la consolidación, el funcionamiento y la preservación de los regímenes democráticos.

- Es herramienta clave para el ejercicio de los demás derechos fundamentales, como el derecho a la participación, a la libertad -religiosa, a la educación, a la identidad étnica o cultural.

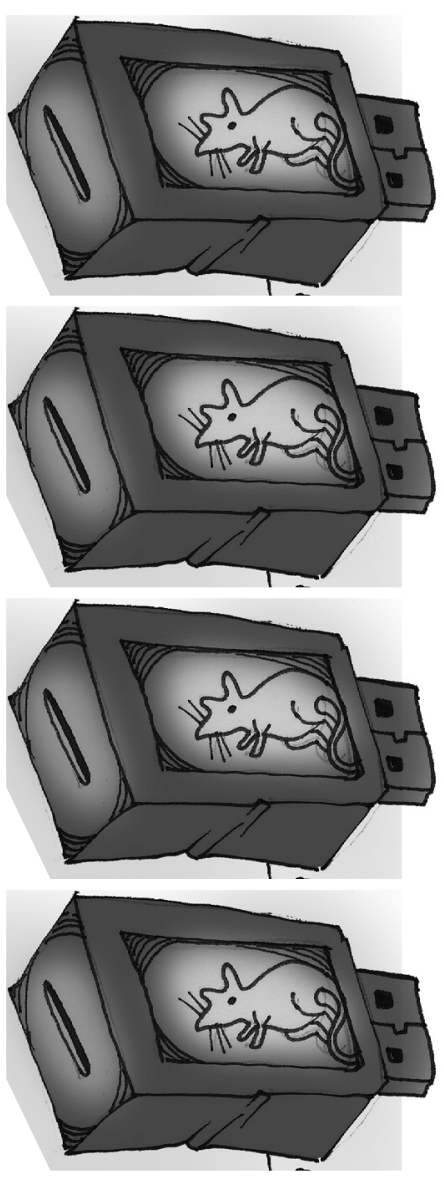




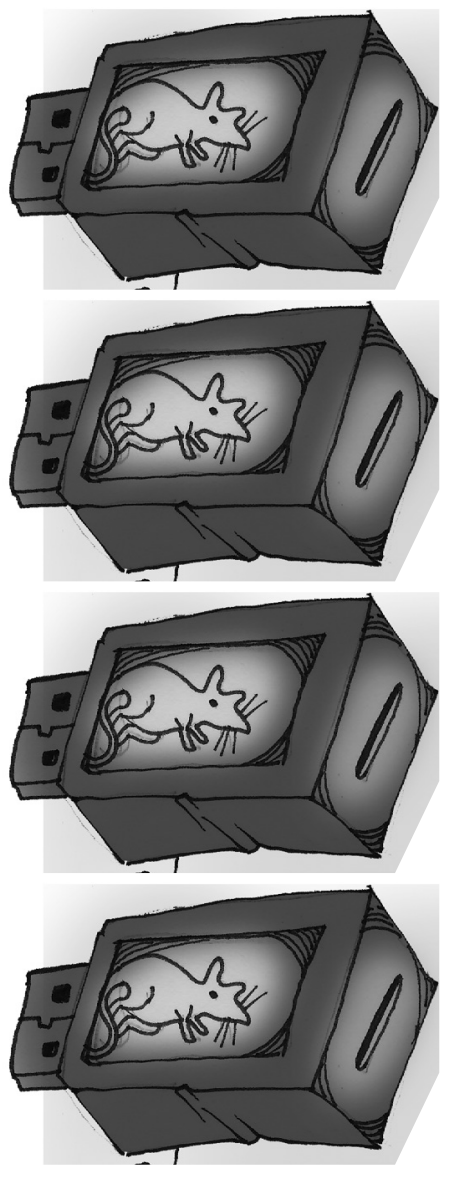

Uno de los aspectos vinculados a la libertad de expresión, es el de investigar y recibir informaciones ${ }^{3}$, que se expresa de manera específica en el derecho de acceso a la información pública. Esto supone un ejercicio activo por parte de un ciudadano para obtener y difundir informaciones públicas a través de diferentes medios de comunicación - un periodista, un investigador social, un líder comunitario-, las que, de acuerdo a la legislación de cada país, puedan entregarse sin que se ponga en riesgo la seguridad nacional o el derecho a la intimidad; a su vez, supone el ejercicio de un derecho desde el ámbito cotidiano de cualquier ciudadano a quien le interese o requiera acceder a una determinada información para resolver un asunto de orden personal: un tratamiento médico, el trámite de su pensión, un alegato judicial, etc... Pero además, el derecho a recibir informaciones supone la instalación de una plataforma institucional que facilite a los ciudadanos el acceso a la información básica de cada organismo estatal en torno a sus funciones, cargos, organigrama, presupuesto, planes de compra, informes de gestión, etc. (páginas web, carteleras, folletos, etc.). Todo ello en aras de facilitar y garantizar el control ciudadano hacia las funciones del Estado.

El derecho de acceso a la información pública se define como el que tiene cualquier persona de acceder y conocer, de manera anónima y sin necesidad de justificación, sobre la existencia de información pública en posesión o bajo control de entidades públicas. Se trata de un derecho fundamental que se sustenta en dos principios: el de máxima divulgación, que supone que el derecho al acceso es la regla y el secreto o limitaciones debe ser la excepción; de otra parte, supone la "prominencia del derecho de acceso a la información en caso de conflictos de normas o falta de regulación”. En segundo lugar, el principio de buena fe, según el cual los encargados de entregar información pública deben, por lo menos, asegurar y garantizar el acceso a los documentos, facilitar los medios para que el solicitante acceda a ellos, actuar diligentemente y promover una cultura de transparencia en su lugar de trabajo ${ }^{4}$.

Teniendo en cuenta que se trata de un derecho fundamental expresado en la carta de las Naciones Unidas, hay una serie de alianzas, redes y mecanismos nacionales e internacionales que propenden para su cumplimiento. Específicamente en el caso latinoamericano, la creación de la Relatoría Especial para la Libertad de Expresión en el año 2007, organismo anexo a la Comisión Interamericana de Derechos Humanos, ha facilitado y propiciado que el tema del acceso a la información - como parte del derecho más amplio de la libertad de expresión- entre a ser parte de la agenda pública de diferentes países y ha promovido la unificación de una reglamentación a partir de la "Ley Modelo Interamericana sobre Acceso a la Información" (2009), que recoge los estándares internacionales en la materia, específicamente del derecho anglosajón (common law). Este soporte ha permitido que en Latinoamérica países como Chile, Argentina y México, entre otros, hayan reglamentado el derecho de acceso a la información en una legislación única.

En el caso colombiano, si bien puede considerarse que este derecho fundamental tiene cabida en algunas reglamentaciones, éstas resultan dispersas, no están suficientemente implementadas ni hay mecanismos eficaces para garantizar su cumplimiento. El pilar del derecho al acceso a la información en el caso colombiano está consignado en el artículo 20 de la Constitución Política de Colombia: "Se garantiza a toda persona la libertad de expresar y difundir su pensamiento y opiniones, la de informar y recibir información veraz e imparcial, y la de fundar medios masivos de comunicación. Estos son libres y tienen responsabilidad social. Se garantiza el derecho a la rectificación en condiciones de equidad. No habrá censura". A su vez, el artículo 74 particulariza en torno al derecho de acceso a documentos públicos: "Todas las personas tienen derecho a acceder a los documentos públicos salvo los casos que establezca la ley. El secreto profesional es inviolable". 
Otra serie de artículos de la Carta Política favorecen también el derecho fundamental del acceso a la información: el artículo 23 -derecho de solicitar informaciones y obtener la respuesta (derecho de petición)-, el artículo 78 - que garantiza el acceso a la información sobre comercialización de bienes y servicios, el artículo 15 - hábeas data, que garantiza a cualquier ciudadano el acceso a sus propios datos en diferentes bases informáticas-. Al lado de estos artículos, hay por lo menos 18 instrumentos nacionales entre leyes, decretos y sentencias de la Corte Constitucional- que van en la misma vía ${ }^{5}$.

No obstante, la Corporación Transparencia por Colombia ha identificado como principales los siguientes problemas en el acceso de información en Colombia: dispersión normativa a nivel legislativo, normas pre- constituyentes, retraso frente a los estándares internacionales, inexistencia de ley estatutaria, ausencia de politica proactiva e integral de transparencia, jurisprudencia constitucional abundante, desconocida e inaplicada ${ }^{6}$. De otra parte, la ley 1437 (enero de 2011) que reglamenta el nuevo Código Contencioso Administrativo, no incluyó de manera explícita el derecho de acceso a la información pública y, por el contrario, regula aspectos que van en contravía de la misma; entre ellos pueden mencionarse la necesidad de explicar las razones para solicitar una determinada información (artículo 16), o la prohibición de acceder a documentos como las hojas de vida o historia laboral de los funcionarios (artículo 24). De acuerdo con Vivian Newman, investigadora del Centro de Estudios de Derecho, Justicia y Sociedad DEJUSTICIA, y una de las redactoras del proyecto de ley presentado por la Plataforma Más Información Más Derechos:

Esta ley 1437 o nuevo código contencioso administrativo, que puede representar avances en otros temas, en materia de acceso a la información repitió las mismas normas consagradas hace más de 25 años y desconoció los avances y estándares internacionales. Con esta nueva normativa se perdieron pues varias oportunidades. No sólo de dar al ciudadano garantías para participar en la democracia y acceso al impulso de sus solicitudes, así como al juez la posibilidad de decidir contra potenciales arbitrariedades, sino en general, se congeló la opción de transparentar lo que sucede en la cosa pública (2011).
Al lado de lo anterior, es necesario mencionar tres elementos que hacen parte de la estructura burocrática del Estado, de la cultura política y de la falta de conocimiento sobre el tema. En primer lugar, lo que se suele denominar el "secretismo" dentro de las instituciones estatales, y que se refiere a una cierta costumbre según la cual los funcionarios, de manera ya interiorizada, niegan o dificultan a cualquier ciudadano el acceso a una información a la que tienen derecho, ya sea porque ignoran la reglamentación o porque hacerlo supone dedicar un tiempo especial para localizar y entregar el documento. En segundo lugar, porque si bien existe una reglamentación sobre el archivo de documentos públicos, no todas las instituciones tienen una infraestructura que permita una catalogación adecuada para que cualquier funcionario pueda acceder a los mismos; es común en estos casos que sea una persona - la secretaria, por ejemplo- que guarde y conozca el archivo del material desde unas lógicas personales que, en caso de ausencia, causa traumas en el funcionamiento de la entidad a la que pertenece.

En tercer lugar, el desconocimiento generalizado por parte de los ciudadanos de los mecanismos más básicos para ejercer el derecho de acceso a la información hace que la demanda del mismo no sea un clamor generalizado, como puede serlo la demanda por servicios de salud, vías de comunicación, subsidios, educación, transporte masivo, entre otros; en ese sentido, podría aplicarse el dicho común de que "ojos que no ven corazón que siente". No obstante, ejercer el derecho de acceso a la información se constituye justamente en una vía que ayuda a garantizar los demás derechos. A propósito de estos aspectos, Vivian Newman plantea:

"Parece que los funcionarios y los encargados de manejar estos datos no saben que el acceso a la información pública es un derecho fundamental consagrado en muchas convenciones internacionales, ratificadas por Colombia y aplicadas con gran tino por nuestra Corte Constitucional. Que tienen la obligación de divulgar proactivamente, y ojalá en un medio de fácil acceso al público (preferiblemente internet) toda la información atinente a su organización, presupuesto, servicios y funcionamiento. Y que además tienen la obligación de contestar a las solicitudes hechas por la ciudadanía sobre información de interés público, sin necesidad de justificación ni identificación del solicitante" (2010). 
En conclusión: teniendo en cuenta las dificultades en el acceso a la información pública en Colombia, a las causas que la originan, al riesgo de que se perpetúen unas prácticas que van en contravía con un régimen democrático y al hecho de que los afectados abarquen un espectro amplio de la sociedad, debe destacarse la pertinencia y la urgencia de una legislación que unifique la ya dispersa en torno al tema. Esto significa que el acceso a la información pública requiere de intervención en tanto política pública, más aún cuando en su formulación como problema ha contado con un proceso de investigación y deliberación desde instancias de la sociedad civil que se han tropezado con iniciativas del ente legislativo.

\section{Actores, escenarios y construcción de agenda pública}

De acuerdo con Pierre Muller, si bien cualquier problema de orden social es susceptible de transformarse en una política pública, para hacerlo se requiere de un trabajo de diversos actores que apelan a una serie de mecanismos para que el tema ingrese efectivamente en la agenda de quienes deben tomar las decisiones (la agenda del decisor). Lograrlo, nos dice Muller, dependerá de múltiples factores propios de la sociedad y del sistema político implicado (2006:59). Citando a Padioleau', plantea tres características a las que debe responder un problema para que logre el acceso a la agenda política:

\section{A. "Unas élites (sindicales, administrativas, politicas), unos ciudadanos que pueden estar más o menos organizados, definen una situación como problemática (porque) perciben unas desviaciones entre lo que es, lo que podría ser o lo que debería ser". \\ в. "... Procedimientos de etiquetaje que lo califican como perteneciente a la esfera de competencia de las autoridades públicas". \\ c. "... Intervención de la sociedad política, incluyendo la opción de no hacer nada" $(2006: 60)^{8}$.}

Por su parte, Remi Lenoir, citado por Roth (2009:58,) distingue tres fases en la construcción de los problemas: a) la transformación de un problema individual vivido como anormal a un problema de orden social; b) la definición del problema en un lenguaje adaptado para que se torne público, a partir de la vocería que del mismo hagan personas o grupos con capacidad e interés para hacerlo; c) la institucionalización del problema a partir del reconocimiento de una intervención pública o política sobre el mismo. Ambos planteamientos coinciden en la importancia que ciertos sectores - élites, en el caso de Padioleau; personas o grupos con capacidad e interés, en el caso de Lenoir- saquen a la agenda pública el problema en cuestión y lideren su posicionamiento como un asunto digno de ser incluido en la agenda de los decisores.
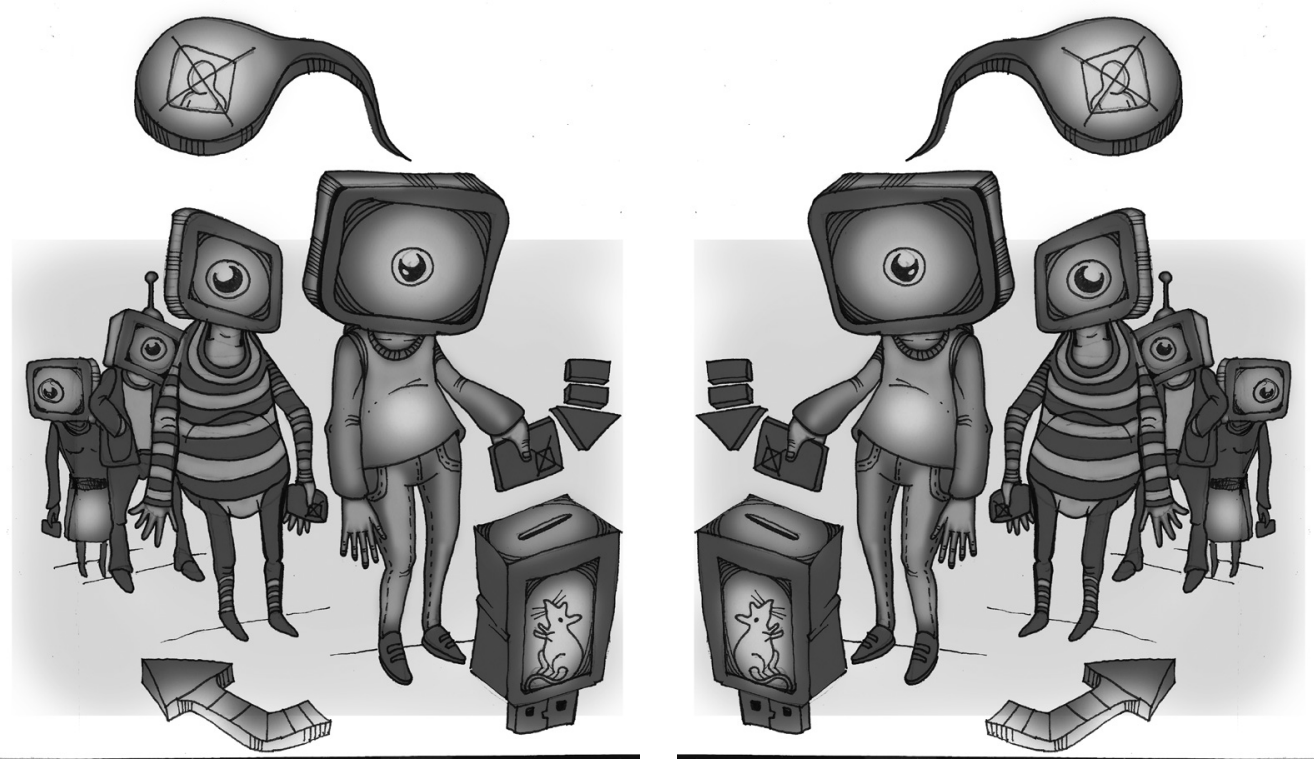
Podríamos decir que en nuestro caso de estudio el surgimiento del problema ha sido progresivo y por múltiples canales (Muller, 2006:61). Por una parte, a través del escenario estatal, compuesto por los congresistas que han presentado el proyecto de ley en curso, pero también por las instancias y actores estatales interesados en responder a estándares internacionales sobre el acceso a la información, la transparencia y la lucha contra la corrupción (Ministerios del Interior, de lasTecnologías de la Información, Cancillería). Por otra parte, por medio del escenario creado por diferentes organizaciones - ONG's, corporaciones y centros académicos- que, por vías diferentes, encuentran que el tema del acceso a la información requiere de una intervención en términos de políticas públicas, específicamente a través del proyecto de ley. Por último, como un elemento integrador y catalizador- una bisagra- entre los actores estatales y los de la sociedad, a través del papel jugado por organizaciones supragubernamentales, gubernamentales y ONG's internacionales.

Las interrelaciones entre agentes estatales, organizaciones de la sociedad civil y organizaciones internacionales, hacen que este caso particular pueda estudiarse desde la teoría de redes (networks theory), específicamente en políticas públicas, la cual (y en coherencia con la teoría mixta) parte del establecimiento de una serie de puentes entre actores estatales y no estatales: "las políticas públicas se conciben como el resultado de interrelaciones e interdependencias entre varias instituciones, grupos e individuos que conforman una red de influencia mutua y en donde las jerarquías reales no siempre son las que formalmente están establecidas" (Roth, 2009:33). Se trata de una perspectiva que hace mayor énfasis en las relaciones entre los actores que en características o atributos individuales: estructuras hibridas de colaboración, de enlace y de apoyo a la actividad política gubernamental (Roth, 2009:34). De acuerdo con Muller, fenómenos que pueden inscribirse en la teoría de redes, dan cuenta de la multiplicación de la sectorización, la fragmentación y la descentralización del Estado, el debilitamiento de las fronteras entre lo público y lo privado, la importancia creciente de actores transnacionales y, más generalmente, la estructura cada vez más compleja de los sistemas de decisión públicos (2006:81).

Ahora bien, aunque desde la teoría de las redes de política pública se hace mayor énfasis en la búsqueda de interrelaciones y acuerdos entre sus diferentes miembros, es evidente que cada uno tiene visiones diferentes en torno al problema que no necesariamente coinciden, lo que puede generar debate y pugnas de intereses no negociables. Muller define como "el referencial de la política pública" (2006:98) la imagen que se quiere dar del problema en cuestión; no es claro, en el tema del acceso a la información pública, que para todos los integrantes del proceso ese referencial sea el mismo: podría decirse que mientras para el proyecto de ley de los senadores la imagen que se quiere dar del tema enfatiza en la transparencia en contratación, para las demás organizaciones se trata de instalarlo como un derecho fundamental.

Teniendo en cuenta los tres bloques que conformarían la extensa red, a continuación presentamos la caracterización de cada uno de ellos y su rol en el entramado del tema del acceso a la información.

\subsection{Actores y escenarios estatales}

Desde hace algún tiempo, el tema de la transparencia se ha constituido en un discurso obligado de los diferentes gobiernos. Bajo lemas como la lucha contra la corrupción, el control social de la acción estatal y la participación ciudadana, considerados como fundamentos que garantizan el funcionamiento de un sistema democrático, se han adelantado proyectos mediáticos que buscan instaurar la agenda estatal en la agenda pública y garantizar el acceso de información a los ciudadanos: v.g. Señal Colombia, Noticiero del Congreso, Gacetas oficiales, páginas web, entre otros. Proyectos como Gobierno en Línea, iniciado durante la administración de Álvaro Uribe Vélez y el de La Urna de Cristal, del presidente Juan Manuel Santos, buscan, a través de las herramientas que ofrece internet, garantizar el acceso de la información oficial a la ciudadanía. 
No obstante, estas iniciativas mediáticas y la ya extensa legislación mencionada en torno a la libertad de expresión y el acceso a la información, el acceso de la ciudadanía a los diferentes canales estatales sigue siendo deficiente, no sólo en las oficinas e instancias de orden nacional, sino también regional y municipal. De hecho, en los estudios periódicos que realiza la Corporación Transparencia por Colombia - filial de la ONG Transparencia Internacional- en diferentes regiones del país se ha encontrado que el tema de acceso a la información es de los que cuenta con los índices más bajos de transparencia. " $A$ partir de las mediciones de los indices de transparencia municipal, departamental, se empieza a dar cuenta que hay vacíos en términos de rendición de cuentas, y que hay dificultades para el acceso a la información pública y en temas de contratación. Estos siempre son los más difíicies y en los que sacan peores índices las entidades", plantea Francy Milena Abril, de Transparencia por Colombia. Otro ejemplo es el estudio realizado por la misma corporación en torno a la credibilidad y grado de información de los colombianos sobre el Congreso de la República (Zúñiga, 2010:46). Sólo el 52\% de los colombianos tiene credibilidad frente a este órgano legislativo y únicamente 3\% de los 970 encuestados, se ha interesado en pedir información al Congreso. La información más solicitada -proyectos de ley y votación de los congresistas en las distintas iniciativases la que perciben como de menor calidad: "91\% de los encuestados consideró como insuficiente la información sobre el estado y avances de los proyectos de ley, y $89 \%$ consideró como insuficiente la información sobre las votaciones de los mismos (...). En síntesis, plantea el informe:

... Estamos ante un panorama en el que muy pocos ciudadanos solicitan información al Congreso de la República de Colombia, y los que la piden, reciben información insuficiente. En otras palabras, la ciudadanía no cuenta hoy con la posibilidad de hacer seguimiento ni al trámite legislativo ni a las decisiones que adoptan sus representantes bien porque la información no se difunde, o porque es de difícil acceso (61).

Teniendo en cuenta las dificultades que entraña el tema en el caso colombiano y la urgencia de responder a estándares internacionales, no resulta extraño que curse en este momento un proyecto de ley sobre el tema. No obstante, el documento presentado por el senador del partido conservador Carlos E. Barriga y cuyo ponente es el presidente de la Comisión Primera del Senado, Eduardo Enríquez, no es el resultado de un estudio que recoja las deficiencias ya existentes ni propone soluciones de fondo ${ }^{9}$. Tres apartes del proyecto pueden dar cuenta de ello: por una parte, éste pretende reglamentar solamente la información relativa a la contratación oficial (artículo $1^{\circ}$.) sin tener en cuenta información derivada de otros procesos y trámites oficiales; por otra parte, el proyecto de ley busca que la información considerada como de reserva conserve tal categoría de manera indefinida y no, como sucede en las reglamentaciones a nivel mundial, por un número determinado de años; de otra parte, el proyecto se ha presentado para que sea considerada como una ley ordinaria y no, como lo exige el hecho de que se esté legislando sobre un derecho fundamental, como una ley estatutaria. Las organizaciones que conforman la plataforma Más Información Más Derechos han realizado un estudio sobre este proyecto de ley y, de acuerdo con Francy Milena Abril, se trata de "una copia mal hecha de la legislación chilena; hay muchas semejanzas con ésta, pero evidentemente no se puede extrapolar sin más al caso colombiano ${ }^{\text {plo }}$. 
Este caso bien puede ser un ejemplo de construcción de una política pública que termina aplazando las soluciones de fondo. Como plantea Murray Edelman, "la construcción de los problemas a veces lleva consigo un efecto perverso de más largo alcance: ayuda a perpetuar o intensificar las condiciones definidas como el problema" (1991:35). Este mismo autor plantea cómo la promoción de determinadas leyes tiende a ocultar, deliberadamente o no, los asuntos de fondo del problema en cuestión, en tanto éstos pueden generar divisiones y disputas entre los interesados. En ese sentido, la promulgación del proyecto de ley buscaría instalar a sus promotores en una estrategia política y mediática. En un proyecto realizado entre el portal de internet lasillavacía.com y la Universidad del Rosario, en el que hicieron un perfil de cada uno de los senadores de la República" (Quién es quién Ojo al Senado), vale la pena considerar la información de los senadores que promueven el proyecto: ambos pertenecientes al Partido Conservador. Su redactor, Carlos E. Barriga, de Norte de Santander, quien lleva tres periodos en esta corporación (2002- 2006, 2006-2010 y desde 2010), con caudal electoral en Norte de Santander, plantea: "Quiero ser recordado como un senador que cumplió con su deber, como un senador propositivo en el tema legislativo. Como un senador que presentó sobre todo proyectos importantes sobre anticorrupción" ${ }^{\prime 2}$. Eduardo Enríquez - integrante de la Cámara de Representantes en los periodos 1998-2002 y 2002-2006; y en el senado entre 2006-2010 y desde 2010 - ponente del proyecto en la Comisión Primera, se presenta así: "Quiero ser recordado por haber sido presidente de la Comisión Primera del Senado y por los resultados que se lograron con el apoyo de mis compañeros". Para los integrantes de la plataforma Más Información Más Derechos, las misiones por las cuales quieren ser recordados ambos senadores pueden influir en que se dé paso al proyecto de ley - el uno como redactor, el otro como ponente y presidente de la Comisión donde se discute-.

\subsection{Actores y escenarios de la sociedad civil}

De acuerdo con la tipología de redes establecida por Rhodes (citado por Muller, 2006:83), los actores que participan en la problematización del tema del acceso a la información por parte de la plataforma Más Información Más Derechos, podrían considerarse como integrantes de una red temática, en tanto se trata de organizaciones con objetivos diferentes que, por vías diversas, han identificado el tema del acceso a la información como de vital importancia para sus proyectos particulares y para la sociedad en general. Si bien la plataforma está compuesta por ocho organizaciones, tres de ellas son las que vienen liderando el proyecto de ley:

- La Fundación para la Libertad de Prensa FLIP, que desde su origen (1998) ha realizado talleres y encuentros con periodistas de diferentes regiones del país. En ese proceso, ha identificado las trabas en el acceso a la información pública como uno de los factores que afecta la libertad de prensa y pone en riesgo la seguridad de los periodistas: "el tema se vuelve importante para la FLIP porque las malas prácticas de acceso a la información o las trabas para el acceso a la información pública son a veces una forma de censura y una forma de generar peligros contra la propia profesión. Una persona que publica noticias sin tener fuentes contrastadas o sin verificar las cosas en los documentos oficiales está más presta a que le hagan cualquier tipo de chantaje o presión judicial"’3.

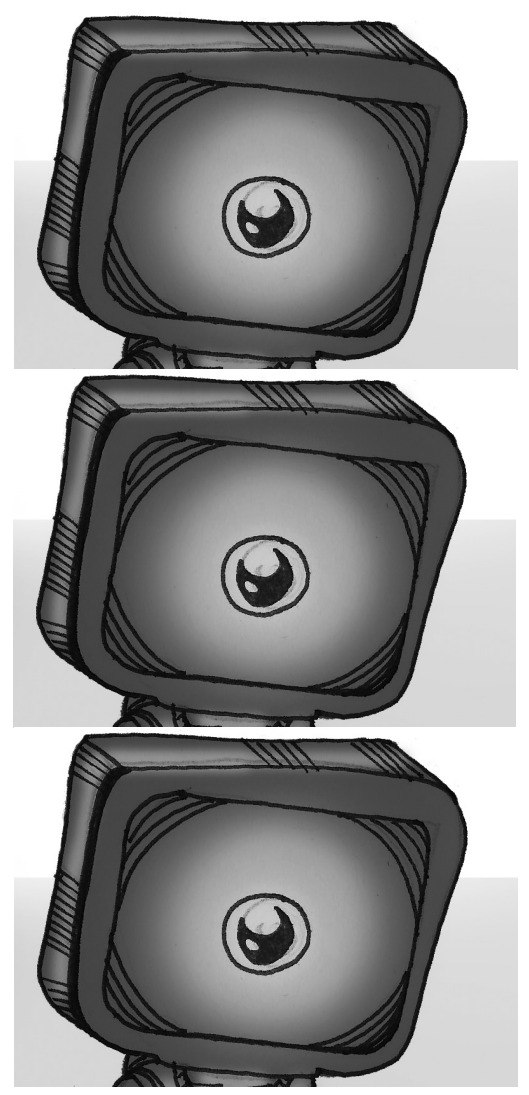


De otra parte, la FLIP ha establecido vínculos con organizaciones periodísticas a nivel internacional que también propenden por el tema del acceso a la información, entre ellas la Red Periodismo por el Acceso a la Información Pública, compuesta por 70 organizaciones de 15 países de la región ${ }^{14}$. Así mismo, hace parte de la Plataforma Regional por la Libertad de Expresión e Información, compuesta por más de 20 organizaciones de la sociedad civil, la que ha establecido convenios de cooperación con instituciones de educación superior de América Latina y cuenta con cerca de 80 especialistas (representantes de ONG's, abogados, académicos, periodistas y otros profesionales) (que) constituyen el capital humano de esta coalición y son fundamentales en sus actividades de cooperación horizontal, cátedras y misiones de incidencia estratégica ${ }^{15}$.

- La Corporación Transparencia por Colombia, fundada en 1998, es el capítulo nacional de la ONG Transparencia Internacional. Su misión es "liderar desde la sociedad civil la lucha integral contra la corrupción y por la transparencia, en lo público y en lo privado, para promover una ciudadanía activa, fortalecer las instituciones

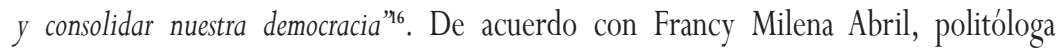
de la Corporación, ésta ha venido trabajando temas relacionados con la rendición de cuentas y a partir de las mediciones de los índices de transparencia municipal, departamental y de las entidades nacionales (año 2002) empieza a hallar vacíos para el acceso a información en temas de contratación y de empleados públicos: (...) a partir de eso y con el apoyo de la embajada de Holanda se empiezan a hacer estudios de caso y sale la pregunta de si es importante o no hacer un proyecto de ley en Colombia.

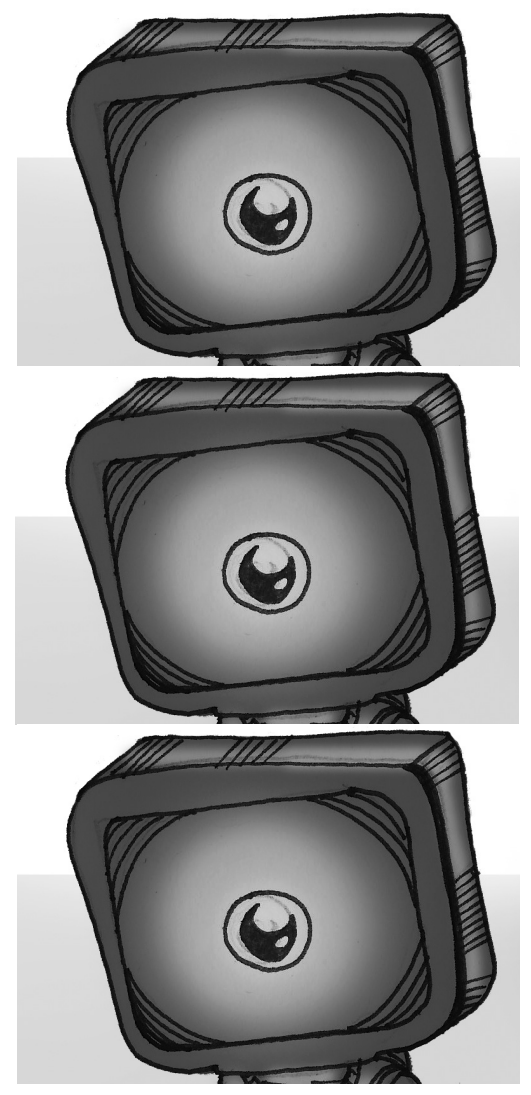

- El Centro de Estudios de Estudios en Derecho, Justicia y Sociedad Dejusticia, compuesto por una serie de investigadores y académicos en derecho y ciencias sociales, se propone intervenir en debates públicos en torno a las instituciones, el derecho y las políticas públicas. ${ }^{17}$ Una de sus miembros fundadores y socios, la abogada Catalina Botero Marino, fue designada desde el año 2009 como Relatora Especial para la Libertad de Expresión de la Comisión Interamericana de Derechos Humanos de la Organización de Estados Americanos. Desde ese lugar, ha liderado el tema de acceso a la información pública y la elaboración y promoción de la Ley Modelo Interamericana sobre Acceso a la Información; además de los informes anuales de la Relatoría, ha promocionado el documento Buenas prácticas judiciales en materia de acceso a la Información en América (2010). De otra parte, en el año 2005 el centro de estudios publicó una investigación realizada entre Catalina Botero, Juan Fernando Jaramillo y Rodrigo Uprimny, Libertad de prensa y derechos fundamentales. Análisis de la jurisprudencia constitucional en Colombia (1992 - 2005). El conocimiento académico de los autores sobre la materia, más el apoyo recibido desde la Relatoría, permitió que la redacción del proyecto de ley, a cargo de Vivian Newman, fuera liderada por Dejusticia. 
Al lado de estas ONG's nacionales - con claros vínculos con organizaciones internacionalesse han integrado progresivamente al posicionamiento del problema del acceso a la información pública y al proyecto de ley las siguientes organizaciones: Plataforma Medios y Democracia, Proyecto Antonio Nariño, Medios para la Paz, Corporación Nuevo Arco Iris, Corporación Ocasa, Centro de Investigación y Educación Popular CINEP, Centro Interdisciplinario de Estudios sobre Desarrollo CIDER, de la Universidad de los Andes, y el Programa Bogotá Cómo Vamos. También cuenta con la asesoría de Programa de las Naciones Unidas para el Desarrollo en Colombia PNUD. La coyuntura que permitió el encuentro y progresiva integración de estas organizaciones fue la campaña lanzada por la Embajada Británica en el año 2009, denominada "Más Información Más Derechos”, que inicialmente arrancó con la participación de la FLIP, Transparencia por Colombia, Medios para la Paz y el CIDER, de la Universidad de los Andes. El propósito era brindar mejores herramientas conceptuales de acceso a la información al Estado colombiano y a la sociedad civil en el marco de otros derechos, sensibilizando a los diferentes actores sobre la importancia del acceso a la información pública como fundamental para fortalecer la gobernabilidad, los derechos humanos y la democracia, así como un mecanismo que permite sembrar confianza ciudadana hacia las instituciones. Además de ejercer un periodismo responsable, ético y de calidad ${ }^{18}$.

Una vez culminada esta campaña, las organizaciones vinculadas continuaron trabajando bajo la modalidad de la plataforma Más Información Más Derechos, desde la cual armaron en conjunto un estudio sobre el tema del acceso a la información para la elaboración del proyecto de ley; para ello, hicieron revisión y recopilación de normas internas, establecieron contactos con organizaciones internacionales y con representantes de México, Chile y Argentina, países donde se tienen las legislaciones más avanzadas sobre el tema. También contaron con el apoyo de la Relatora Especial para la Libertad de Expresión de la OEA, Catalina Botero, y el de la presidenta de la Plataforma Regional para la Libertad de Expresión y de Información (Carolina Bonfil).
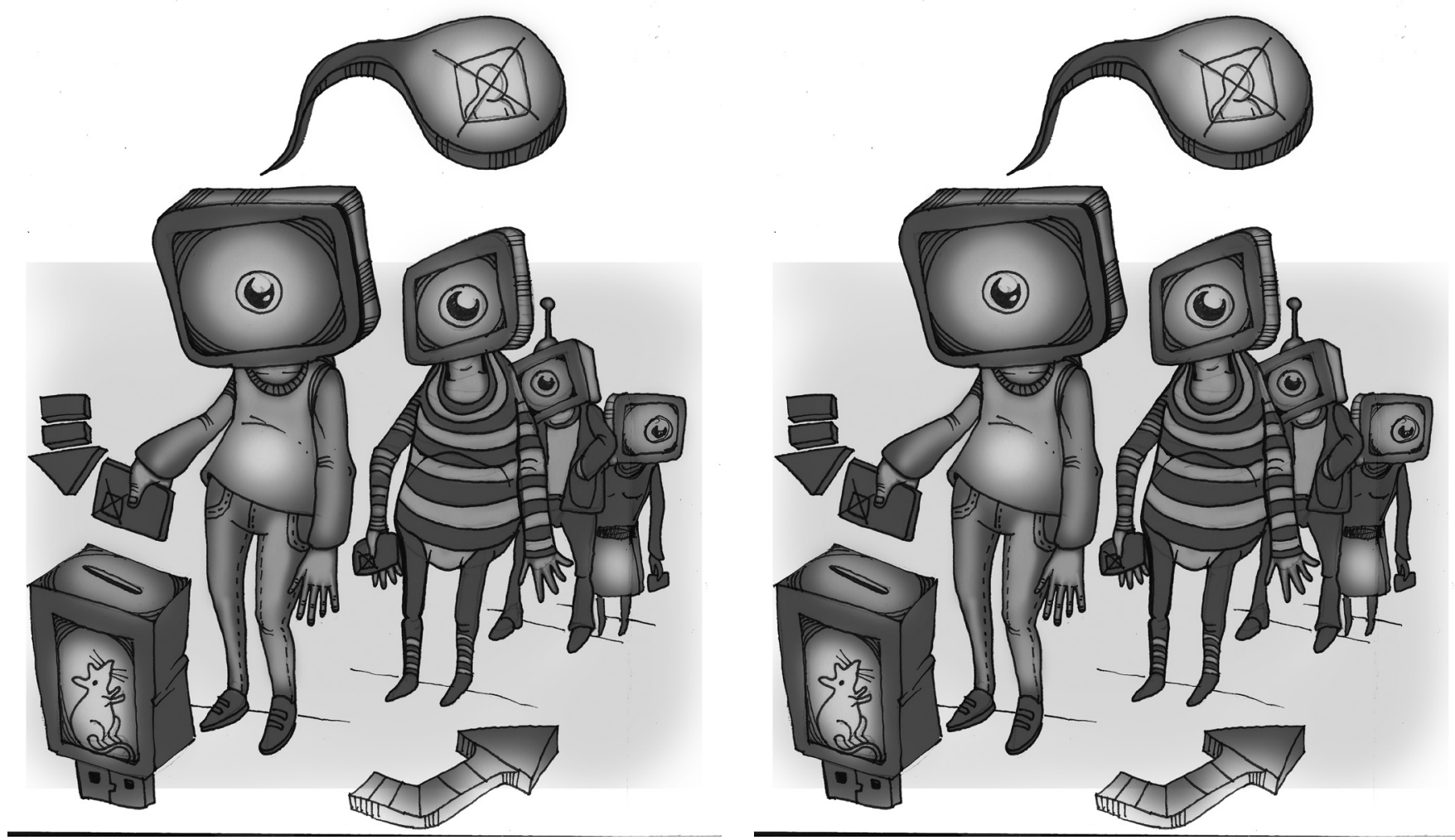
A pesar de este proceso, solamente en diciembre del año 2011 se enteraron de la existencia del otro proyecto de ley liderado por los senadores Barriga y Enríquez, justamente cuando empezaban a diseñar la estrategia de incidencia en el Senado y en el gobierno nacional. Después de algunos meses de búsqueda del senador Barriga, lograron reunirse con el ponente del proyecto, Eduardo Enríquez, y con sus asesores: Les expusimos las falencias de su proyecto y les contamos el proceso de la Plataforma - los informes, talleres, reuniones realizadas-. Nos dijeron 'ustedes duraron tres años haciendo esto; nosotros en un día no lo vamos a hacer'.

El acuerdo al que llegaron fue la realización de un foro donde se presentarían los comentarios al proyecto de ley y se trataría de influenciar la votación para que no sea aprobado. Al foro asistirían el Ministro del Interior, el Procurador General y el Ministro de Hacienda, por las consecuencias políticas, logísticas y presupuestales que supondría la aprobación de la ley. De otra parte, desde la plataforma Más Información Más Derechos, en la actualidad se ha iniciado lobby para lograr citas individuales con los demás integrantes de la Comisión Primera, con el fin de presentarles las objeciones del proyecto radicado e influir para que no prospere.

\subsection{Papel de las organizaciones internacionales}

Como se desprende de lo anterior, ha sido fundamental el apoyo de las organizaciones internacionales a las organizaciones sociales nacionales para el planteamiento del tema de acceso a la información pública como un asunto importante y susceptible de generar una política pública en Colombia. Estas organizaciones pueden categorizarse en tres tipos:

A. Estatales: Embajada Británica y Embajada de los Países Bajos.

B. Supragubernamentales: Organización de los Estados Americanos OEA, a través de la Relatoría Especial para la Libertad de Expresión, y el Programa de las Naciones Unidas para el Desarrollo en Colombia PNUD.

c. Redes y Organizaciones No Gubernamentales: Alianza Regional por la Libertad de Expresión y de Información y la Red de Periodismo por el Acceso a la Información Pública. Además, debe tenerse en cuenta que algunas de las organizaciones promotoras del proyecto de ley tienen convenios de cooperación con ONG's internacionales.

Este apoyo, además de verse reflejado en recursos provenientes de la cooperación internacional y en asesoría académica y jurídica para la elaboración del proyecto de ley, supone también una presión para que el tema sea posicionado desde la perspectiva de derecho fundamental, acogiéndose a la reglamentación internacional. El fenómeno de las redes de defensa transnacional, centradas en principios que suponen un cierto carácter universal - en este caso la libertad de expresión y en ella el acceso a la información- buscan justamente, a través de políticas de información, construir un marco cognitivo para socializar el tema de interés y persuadir o presionar a los "actores meta" con capacidad de decisión en el tema (Risse, 2000). 


\section{Formulación de soluciones: las relaciones de fuerza}

Si bien, como ha sido expuesto antes, el proceso de los dos proyectos de ley es aún incipiente, el hecho de que ya se haya generado un primer encuentro entre agentes estatales y organizaciones sociales para debatir el proyecto de ley en trámite, y de que se planee un foro en la Comisión Primera, con participación de los diferentes actores, incluidos funcionarios de alto nivel, supone el inicio de una nueva fase de deliberación. En ella, los senadores ponentes establecen interrelación con organizaciones académicas y sociales expertas en el tema; por su parte, éstas establecen interlocución oficial con la instancia formal de "los decisores". El cruce entre la experticia de los políticos y funcionarios públicos, con la experticia de los activistas y académicos supondrá la confrontación de dos marcos interpretativos diferentes en torno a los objetivos de la ley. Un ejemplo de ello es el de la definición del principio de transparencia - expuesto en el proyecto de ley de los senadores: implica el desarrollo de la función pública con claridad, nitidez, refulgencia, limpieza, pureza, es decir, todo lo contrario a oscuridad, nebulosidad, turbiedad, equivocidad, suciedad, fuliginosidad" (artículo $4^{\circ}$ ). Una "descripción de diccionario", dice Francy Milena Abril, de Transparencia por Colombia.

Como plantea Majone, en este ejercicio de confrontación de posiciones, es fundamental no restringirse al discurso académico especializado sino también a la utilización de recursos retóricos que logren persuadir al otro. A su vez, en tanto se trata de un debate en el que hay intereses diferentes, se tratará también, de ser necesario, de transformar las propias opiniones a partir del aporte del otro (1997: 42). La plataforma Más Información Más Derechos plantea que algunos de los aspectos del proyecto de ley que defienden no son negociables: la prevalencia del derecho al acceso a la información de interés público frente a protección de la intimidad o a la seguridad nacional, su carácter de ley estatutaria, el carácter temporal de la reserva de información pública y la vinculación de partidos políticos como "sujetos obligados".

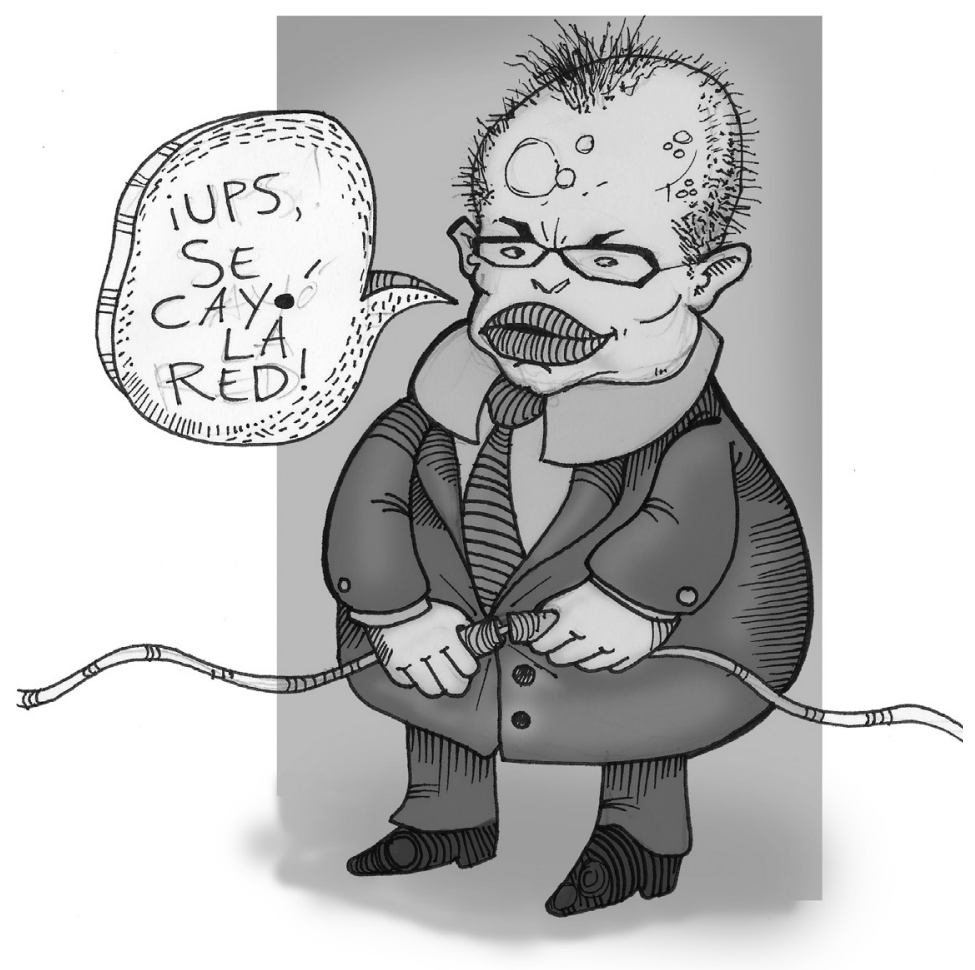


Estas son algunas de las soluciones propuestas al tema por ambos proyectos. Se advierten diferencias abismales entre ambos proyectos de ley en lo relativo a las soluciones que proponen para responder al problema del acceso a la información como política pública' ${ }^{19}$ :

\begin{tabular}{|c|c|c|}
\hline Tema & $\begin{array}{c}\text { "Proyecto de ley de transparencia y acceso a la } \\
\text { información pública nacional", del senador } \\
\text { Carlos Barriga. }\end{array}$ & $\begin{array}{l}\text { "Proyecto de ley del derecho de acceso a la } \\
\text { información" de la plataforma Más Información Más } \\
\text { Derechos. }\end{array}$ \\
\hline Campo de aplicación & Exclusivamente para los temas de contratación & $\begin{array}{l}\text { Toda entidad o persona pública en las tres ramas del } \\
\text { poder y en todos los niveles de estructura estatal: } \\
\text { central y descentralizada; de orden nacional, } \\
\text { departamental, municipal y distrital). } \\
\text { Entidades estatales independientes o autónomas. } \\
\text { Personas privadas que reciben fondos o beneficios } \\
\text { públicos nacionales mayores al } 50 \% \text { de su presupuesto. } \\
\text { Partidos, movimientos políticos o grupos significativos } \\
\text { de ciudadanos. }\end{array}$ \\
\hline $\mathrm{DDHH}$ & $\begin{array}{l}\text { Plantea que la ley estará limitada al respeto de los } \\
\text { DDHH, principio de reserva legal, honra, buen } \\
\text { nombre, intimidad personal y familiar y el debido } \\
\text { proceso. }\end{array}$ & $\begin{array}{l}\text { Como derecho fundamental, y de acuerdo al principio } \\
\text { de proporcionalidad: si el perjuicio al interés general es } \\
\text { mayor, debe aportarse la información de reserva. }\end{array}$ \\
\hline Tipo de ley & Ordinaria & $\begin{array}{l}\text { Estatutaria, por tratarse de un derecho fundamental. } \\
\text { Esto quiere decir que está por encima de cualquier } \\
\text { otra ley que la contradiga. }\end{array}$ \\
\hline $\begin{array}{l}\text { Publicidad de la } \\
\text { información oficial }\end{array}$ & $\begin{array}{l}\text { Debe reposar en la página web de cada entidad por } \\
\text { un periodo de tres meses. }\end{array}$ & $\begin{array}{l}\text { Debe reposar en la página web de cada entidad por } \\
\text { tiempo indefinido, teniendo en cuenta las } \\
\text { posibilidades de almacenamiento de información } \\
\text { de la red. }\end{array}$ \\
\hline $\begin{array}{l}\text { Información de } \\
\text { carácter comercial y } \\
\text { económico }\end{array}$ & $\begin{array}{l}\text { Incluye como causal de reserva parcial o total } \\
\text { derechos de carácter comercial o económico. }\end{array}$ & $\begin{array}{l}\text { No se debe exonerar información de carácter } \\
\text { comercial o económico. Los casos especiales deben } \\
\text { establecerse de manera precisa y taxativa. }\end{array}$ \\
\hline $\begin{array}{l}\text { Documentos en el } \\
\text { ámbito de la defensa } \\
\text { nacional o estrategia } \\
\text { militar. }\end{array}$ & Su carácter reservado o secreto será indefinido. & $\begin{array}{l}\text { Las reservas serán temporales. Doce años con } \\
\text { posibilidad de otros } 12 \text { años prorrogables. }\end{array}$ \\
\hline Implementación & $\begin{array}{l}\text { Se creará el Consejo para la Transparencia Nacional, } \\
\text { adscrito a la Vicepresidencia de la República. }\end{array}$ & $\begin{array}{l}\text { Propone la creación de una Delegada de } \\
\text { Información, adscrita a la Procuraduría General de } \\
\text { la nación. }\end{array}$ \\
\hline Educación & Desde el Consejo se capacitará a los funcionarios.. & $\begin{array}{l}\text { Propone incluir en los pensum escolares una cátedra } \\
\text { sobre el derecho de acceso a la información. }\end{array}$ \\
\hline
\end{tabular}


En síntesis, el proyecto de ley presentado por el senador Carlos Barriga no alcanza una dimensión integral de las implicaciones de una política pública en acceso a la información. Por el contrario, algunos de sus artículos van en contravía del mismo (v.g. reservas legales indefinidas) y su implementación no garantiza el cumplimiento de la ley, en tanto el Vicepresidente de la República, quien presidiría el Consejo para la Transparencia Nacional, no tiene funciones decisorias ni disciplinarias. Con respecto al proyecto de ley de la plataforma Más Información Más Derechos, es importante hacer las siguientes consideraciones:

- Toma en consideración la noción de interés general, del cumplimiento de los Derechos Humanos y del Derecho Internacional Humanitario para el derecho de acceso a la información, por encima de las reservas legales en casos de seguridad nacional y operaciones militares. En un contexto de conflicto armado como el colombiano, este aparte tiene una importancia significativa, pues permite proteger a la población civil de operaciones militares estatales que por acción u omisión generen desmanes. En el caso demostrado de algunas masacres cometidas por grupos paramilitares con el apoyo del Ejército colombiano... Buenas prácticas.

- Teniendo en cuenta que grupos económicos privados hoy prestan servicios que antes correspondían a responsabilidades del Estado, ya sea a través de los servicios públicos, contratación de obras, etc. deben ser claros los mecanismos para el acceso de información en aquellas empresas donde hay inversión de recursos estatales, e incluso que pueda accederse a información de cualquier empresa que cuente con inversión pública incluso menor al 50\%.

- Será importante revisar en la formulación del proyecto el modo como algunos de sus artículos chocan con el de otros proyectos, por ejemplo el de la Nueva Reforma Estatutaria o el proyecto de ley de Inteligencia y Contrainteligencia, de modo que puedan prevenirse futuras confusiones para el cumplimiento de la reglamentación.

- En términos de implementación, resulta clave adelantar el proyecto con las instancias que garantizarán su buen funcionamiento. El hecho de que sea en la Procuraduría General de la Nación permite que se cuente con una estructura administrativa que facilite la implementación de la nueva Delegatura.
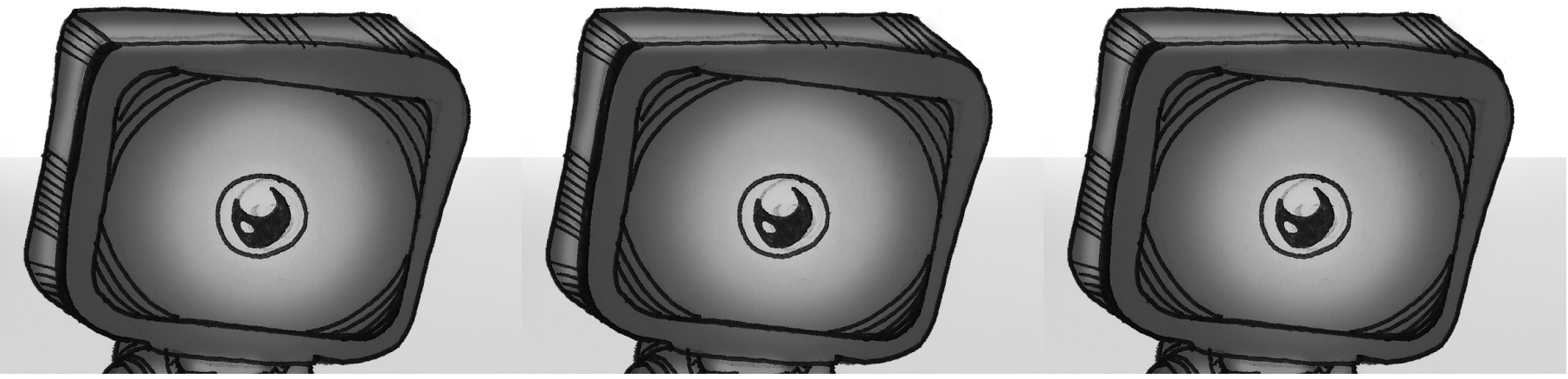


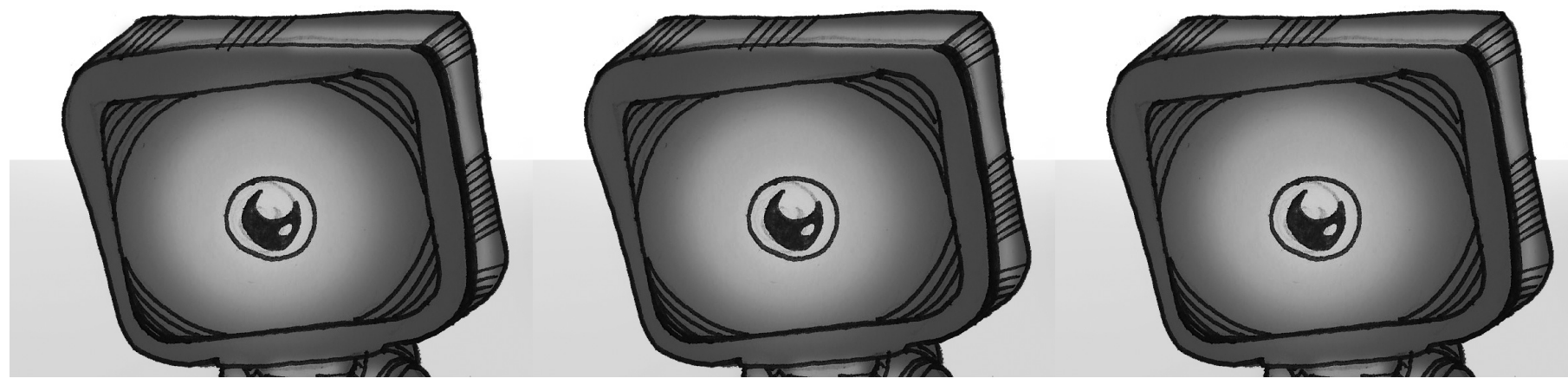

\section{Algunas conclusiones}

A pesar de que hay dos iniciativas en curso en torno al tema del acceso a la información pública, puede considerarse su proceso aún incipiente, ubicado, de acuerdo al modelo del ciclo de políticas públicas (policy cicle) en su primera fase. En ella se juega fundamentalmente el posicionamiento del marco desde el cual quiere visualizarse el problema: Como un asunto limitado (temas de contratación) y limitante (apoyo a reservas legales) en el caso del proyecto del senador Barriga, y como un derecho fundamental, en el caso de la plataforma Más Información Más derechos. Debe tenerse en cuenta que finalmente se logró un proceso de negociación que permitió la adhesión al proyecto de la Plataforma, lo que indica que desde el punto de vista de las organizaciones sociales fue clave acudir a estrategias de argumentación que persuadieran a los "decisores" en torno a las claves fundamentales de una política pública unificada. Un importante mecanismo de presión para ello es el contexto internacional, en el que se ha avanzado jurídicamente en distintos países de América Latina así como en otra zonas del mundo y en el que organizaciones como la OEA y las Naciones Unidas (desde el PNUD) pueden ejercer presión ante el Estado colombiano para que cumpla con los estándares internacionales en el tema; de ahí que oficinas como el Ministerio del Interior, el Ministerio de Tecnologías de la Información o la Cancillería puedan promover el proyecto desde el Congreso de la República.

De acuerdo con los integrantes de la plataforma Más Información Más Derechos, el proyecto del senador Barriga no tenía muchas posibilidades de prosperar, aun pasando los debates que requería, pues su carácter de derecho fundamental debía ser reglamentado como norma estatutaria (caso en el cual, de ser aprobado, la Corte Constitucional podría derogarlo). Ahora bien, a pesar de las campañas informativas (postales, folletos, páginas web, etc.) y talleres de socialización en diferentes ciudades del país (Bogotá, Cali, Medellín, Barranquilla y Pasto), el tema aún carece de posicionamiento en los medios de comunicación, no obstante que éstos serían uno de sus principales beneficiarios ${ }^{20}$ : aún el despliegue mediático sobre el tema es insuficiente. Su construcción para las grandes audiencias como "problema social" que requiere ser resuelto aún es precario, su conversión en noticia en la que se recogen casos particulares que reflejan un anomalía de orden más general se topa con coyunturas legislativas y mediáticas que lo ubican por lo pronto en un lugar secundario: ley de víctimas, ley de tierras, proyecto de referéndum de cadena perpetua a violadores y asesinos de niños, entre otros. Paradójicamente, el lobby de la plataforma Más Información Más Derechos en el senado de la República y en organismos estatales, probablemente deba sumarse al lobby en los medios de comunicación más influyentes del país. 


\section{Notas}

1 La secretaría Técnica de la Plataforma ha estado a cargo desde hace dos años de la Corporación Transparencia por Colombia y en los próximos meses será asumida por la FLIP.

2 En: Informe Anual de la Comisión Interamericana de Derechos Humanos 2008, Volumen III. Informe de la Relatoría Especial para la Libertad de Expresión, 25 de febrero de 2009. Pg. 4

3 Quizás una de las imprecisiones del artículo 19 de la Carta de las Naciones Unidas es que no específica que se trata de informaciones de carácter público, es decir, originadas en las diferentes instancias estatales No obstante, las limitaciones de acceso a la información de entidades privadas merecería discusiones de fondo, en tanto la injerencia de las mismas afectan a sectores amplios de la sociedad y han terminado por remplazar funciones que tradicionalmente cumplía el Estado. Un caso paradigmático es el de las telecomunicaciones: servicios de telefonía celular y fija, canales privados de televisión, entre otros.

4 En: Documento del Seminario sobre el Derecho de Acceso a la Información. Plataforma Más Información Más Derechos. Pasto, 24 de mayo de 2011. Pg.11

5 Ibídem, pg.29

$6 \quad$ Ibídem, pg.34

7 J.G. Padioleau. L'État au concret, París, Puf, 1982, p.25

8 A propósito de este "no hacer nada", otro autor, Murray Edelman (citando a Peter Bachrach) se refiere a las "no- decisiones": "A veces se producen porque grupos políticos poderosos pueden bloquear la consideración de las prácticas con las que ellos se benefician, pero esa forma de no- decisión por lo general tiene poca vida (1991:20).

9 Debe tenerse en cuenta que este trabajo se ha realizado contando sólo con el punto de vista testimonial de integrantes de la plataforma Más Información Más derechos, y de la escasísima información sobre el proyecto de ley del senador Carlos E. Barriga.

10 Entrevista realizada a Francy Milena Abril

11 http://www.lasillavacia.com/historia/las-caras-del-senado-23195

12 http://www.lasillavacia.com/ojoalsenado/perfil/16

13 Emmanuel Vargas, abogado de la FLIP.

14 Ver: http://www.periodismo-aip.org

15 http://www.flip.org.co/content_display/3/731.html

16 http://www.transparenciacolombia.org.co/QUIENESSOMOS/

$17 \mathrm{http}: / /$ dejusticia.org/index.php

18 http://www.flip.org.co/content_display/3/730.html

19 Este cuadro se elaboró retomando elementos de los estudios realizados por la FLIP, Transparencia por Colombia y Dejusticia sobre el proyecto de ley presentado por el senador Barriga.

20 Ahora bien, esto supondrá abrir también la caja negra de la negociación de pauta publicitaria entre medios de comunicación y el estado.

\section{Referencias}

Botero, Catalina; Jaramillo, Juan Fernando, Uprimny, Rodrigo. (2005), Libertad de prensa y derechos fundamentales. Análisis de la jurisprudencia constitucional en Colombia (1992- 2005), Legis, Bogotá.

Edelman, Murray. (2002). La construcción del espectáculo politico, Manantial, 1ª Edición, Buenos Aires.

Majone, Giandomenico. (1997). Evidencia, argumentación y persuasión en la formulación de políticas, Colegio Nacional de Ciencias Políticas y Administración Pública, Fondo de Cultura Económica, México.

Muller, Pierre. (2006). Las políticas públicas, Universidad Externado de Colombia, 2ª Edición, Bogotá.

Roth, André- Noël. (2009). Políticas Públicas. Formulación, implementación e valuación, Aurora, $7^{\mathrm{a}}$. Edición, Bogotá.

Risse, Thomas. (2000). The Power of Norms versus the Norms of Power:Transnational Civil Society and Human Rights. En: The Third Force. The rise of Transnational Civil Society, Japan Center for International Exchange, Tokyo, Carnegie Endowment for International Peace, Washington D.C.

Unidad de Análisis Político del Instituto Centroamericano de Estudios Políticos INCEP. (2002). "Cómo hacer un análisis de coyuntura (Elementos para el análisis político)", Cuadernos de Formación para la Práctica Democrática No.5, Guatemala.

Zúñiga, Paola. (2010), Informe de Transparencia por Colombia. Evaluación del grado de apertura informativa del Congreso de la República de Colombia. En: Foro Internacional Transparencia y Apertura Informativa del Poder Legislativo. Memorias. Colección Cuadernos de Transparencia. Embajada de Noruega, Corporación Transparencia por Colombia, Bogotá. 


\section{Documentos}

Código de Procedimiento Administrativo y de lo Contencioso Administrativo - Ley 1437 de 2011

Constitución Política de Colombia.

Informe Anual de la Comisión Interamericana de Derechos Humanos 2008, Volumen III. Informe de la Relatoría Especial para la Libertad de Expresión, 25 de febrero de 2009.

Ley Modelo Interamericana sobre Acceso a la Información. Consejo Permanente de La Organización de los Estados Americanos. Comisión de Asuntos Jurídicos y Políticos. 28 de Abril de 2010.

Proyecto de Ley 2010 de 2010- Senado. "Por medio del cual se crea la ley de transparencia y acceso a la información pública nacional, y se dictan otras disposiciones". Proyecto de Ley de Acceso a la Información, 2011. Dejusticia, Transparencia por Colombia, Embajada de los Países Bajos. Seminario sobre el Derecho de Acceso a la Información. Plataforma Más Información Más Derechos. Pasto, 24 de mayo de 2011.

Seminario Acceso a la Información: estándares internacionales y su aplicación en Colombia. Proyecto Antonio Nariño, Embajada de Suiza y Relatoría Especial para la Libertad de Expresión, Cali, 23 de septiembre de 2009.

\section{Columnas de opinión}

Newman, Vivian, En este 28 de septiembre, Día Internacional del Derecho a Saber, se raja el acceso a la información pública en Colombia. En: Semana.com, 27 de septiembre de 2010.

De cómo pedir información pública y morir en el intento! En: lasillavacia.com, 27 de febrero de 2011.

\section{Entrevistas}

Francy Milena Alba, politóloga de Transparencia por Colombia (mayo 17 de 2011).

Emmanuel Vargas, abogado, Fundación para la Liberta de Prensa FLIP (mayo 20 de 2011).

\section{Páginas web}

www.lasillavacia.com

www.dejusticia.org

www.transparenciaporcolombia.org

www.flip.org

www.periodismo.aip.org
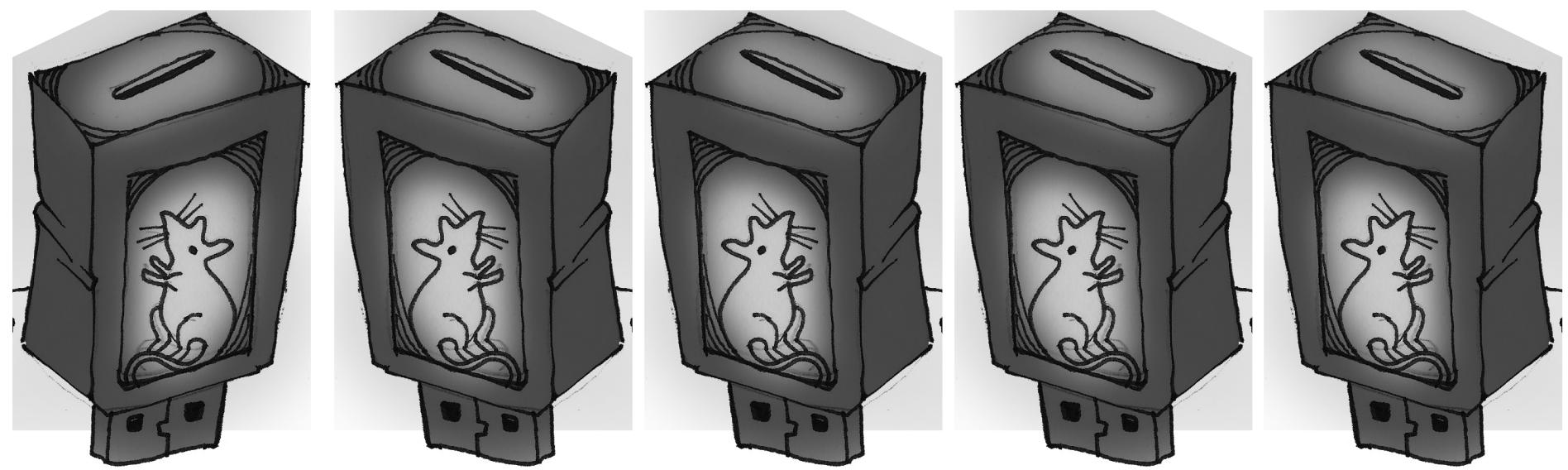